\title{
Compensatory canine angulation in angle Class II and III patients
}

\begin{abstract}
Mauro Carlos Agner Busato(a) Marcos Rogério de Mendonça(b) Alex Luiz Pozzobon Pereira ${ }^{(a)}$ Pedro Marcelo Tondelli(a) Osmar Aparecido Cuoghi(b)
\end{abstract}

(a) Graduate Student (PhD); (b) PhD, Assistant Professor - Department of Orthodontics, School of Dentistry of Araçatuba, São Paulo State University (UNESP), Araçatuba, SP, Brazil.

\section{Corresponding author:}

Mauro Carlos Agner Busato

Departamento de Ortodontia, Faculdade de Odontologia de Araçatuba (FOA - UNESP) Rua José Bonifácio, 1193

Araçatuba - SP - Brazil

CEP: 16015-050

E-mail:mcabusato@uol.com.br

Received for publication on Sep 03, 2008 Accepted for publication on Nov 1 1, 2008
Abstract: The aim of this study was to evaluate the occurence of compensation in mesiodistal axial inclinations of canines in skeletal malocclusions patients. The sample consisted of 25 Angle Class II, division 1 malocclusion (group 1) and 19 Angle Class III malocclusion patients (group 2). After measurement of dental angulations through a method that associates plaster model photography and AutoCad software, comparisons between the groups were performed by T-test for independent samples. Results showed that there was no statistically significant difference $(p \leq 0.05)$ between groups, when maxillary canine angulations were compared. Regarding the mandibular canines, there was a statistically significant difference in dental angulation, expressed by $3.2^{\circ}$ for group 1 and $0.15^{\circ}$ for group 2. An upright position tendency for mandibular canines was observed in the Angle Class III sample. This configures a pattern of compensatory coronary positioning, since the angulation of these teeth makes them occupy less space in the dental arch and consequently mandibular incisors can be in a more retracted position in the sagittal plane.

Descriptors: Orthodontics; Dental models; Cuspid; Malocclusion, Angle Class II; Malocclusion, Angle Class III. 


\section{Introduction}

The normal occlusion concept, which has been attributed to typical dental positions in subjects with excellent occlusion, was described by Andrews ${ }^{1,2}$ $(1972,1989)$ and has become an Orthodontics classic. In addition, Andrews' work has established a new concept for diagnosis and goals that should be reached in orthodontic treatment. Among the six keys to normal occlusion, the correct mesiodistal position of the dental crown's long axis contributes to reaching the balance of the occlusion and of the stomatognathic system. ${ }^{3,4}$ Moreover, this axial positioning constitutes a relevant factor for obtaining teeth alignment in the respective osseous base and long-term treatment stability. ${ }^{3-5}$ This parameter is adopted to define the orthodontic treatment excellence and can be evaluated clinically or in plaster model analysis, before, during and after orthodontic therapy. ${ }^{2,6-9}$

The concern about the dental angulations has historically been observed in Holdaway's attitude. ${ }^{4}$ This author, in 1952, had suggested that the orthodontic accessories must be angulated during appliance installation, in substitution of artistic bends in the anterior arch segment. ${ }^{4}$ In 1970, Lawrence F. Andrews, ${ }^{1}$ had developed the first totally preadjusted orthodontic appliance (Straight wire) in which the dental angulations were incorporated in the bracket design, thus eliminating the second order bends, as well as the need for an angulated bonding of the brackets.

According to Proffit ${ }^{5}$ (1995), skeletal Angle Class II and III malocclusions could be treated in different manners, depending on the associated characteristics of the sagittal problem, like the anteroposterior discrepancy severity and the patient's age and cooperation. If there is an accentuated skeletal discrepancy, with facial aesthetics involvement, these malocclusions must ideally be treated by a combination of orthodontics and orthognathic surgery. On the other hand, if there is a mild sagittal skeletal discrepancy, with compensation of dental labiallingual inclinations and without the patient's facial complaint, treatment may be performed by orthodontic camouflage. Thus, it would be necessary to maintain or accentuate preexisting labial-lingual inclinations (torque), obviously respecting biological and periodontal limits. ${ }^{1-3}$ In the same way, the anterior teeth angulations, mainly that of canines, define the space that teeth occupy in the dental arch (Figure 1) and have a direct impact on incisors inclinations and overjet. ${ }^{1,3,8-10}$

The aim of this study was to compare the angulation of maxillary and mandibular canines in skeletal Class II and III malocclusions, in patients that were referred for camouflage orthodontic treatment, with the intention of determining the existence of a specific angulation pattern of canines in the evaluated malocclusions.

\section{Material and Methods}

Retrospective sample selection was obtained from one of the authors' private clinic files and from the Orthodontics Department of the West Paraná State University, Cascavel, PR, Brazil.

The sample consisted of 44 patients, with 25 Angle Class II, Division 1 malocclusion patients (group 1), and 19 Angle Class III malocclusion patients (group 2). The inclusion criteria were based on the following characteristics:

- Patients should present bilateral Angle Class II, division 1 and Class III malocclusions, observed through the canine and molar relationship in plaster models, associated with skeletal maloclu-

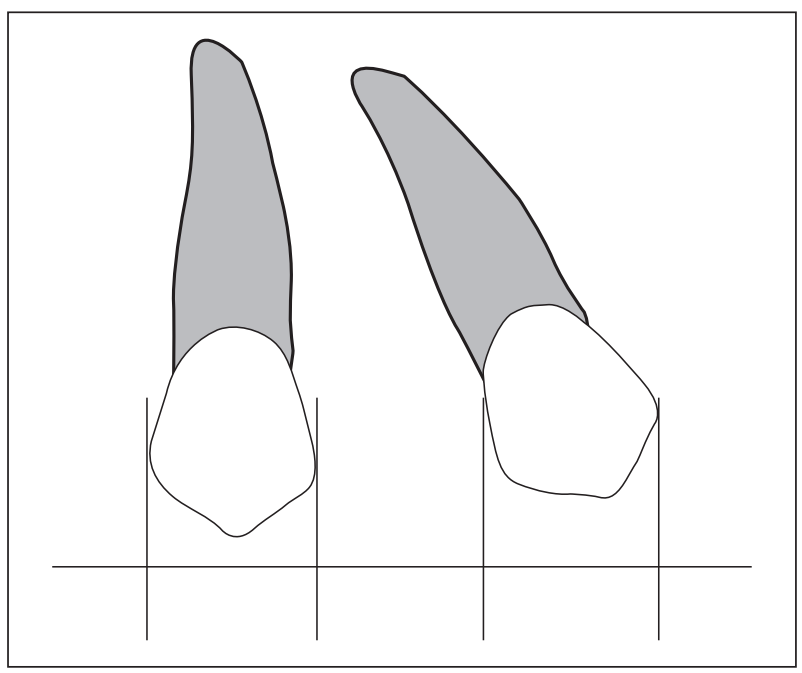

Figure 1 - Increased anterior tooth angulation generates increased tooth space occupation in the dental arch. The opposite is also true. 
sion diagnosed in facial analysis and in the lateral cephalogram, with ANB angles greater than or equal to $5^{\circ}$ for group 1 or less than or equal to $-1^{\circ}$ for group 2 .

- Absence of dental agenesis, extractions or supernumerary teeth.

- Patients should present complete permanent dentition in occlusion (except third molars).

- Absence of clinically significant maxillary and mandibular crowding (Little ${ }^{11}$ index less than or equal to $3.5 \mathrm{~mm}$ ).

- Absence of diastemata.

- Good quality of plaster models (teeth reproduction).

- No history of previous orthodontic treatment.

- Canines in the plaster models should be wellaligned and in function. Canines in infra-labialinclination or with rotations were excluded.

The average age of group 1 and group 2 was 16.1 years and 21.3 years, respectively.

Coronary angulation measurements were executed through a method that associates plaster model standard photographs (Coolpix 995, Nikon Corporation, Tokyo, Japan) and the Engineering software Autocad 2000 (AutoDesk Co., San Rafael, CA, USA) (Figures 2 and 3). This method proved more precise and reproducible than the Andrews' method. ${ }^{1}$ For group 1, fifty maxillary canine photographs were obtained and 36 maxillary canines were photographed to compose the group 2 sample. Mandibular canine photographs totaled 42 and 38, respectively for groups 1 and 2 . To ensure plaster model positioning reproducibility, a rigid plastic template trimmed in the canine area was used, on which a civil construction leveling instrument was adhered, in order to make the plaster model occlusal plane parallel to the floor. The plastic template was placed on the occlusal surfaces of the teeth in order to lie over the incisal edges of both central incisors and on the cusp tips of the maxillary and mandibular molars (Figures 4 and 5).

Once the image was captured, the canine crown's vestibular long axis (EVCC) and occlusal plane were traced in the AutoCAD 2000 software, according to Andrews ${ }^{1,2}$ (1972, 1989) (Figures 6 and 7). Tracings of the dental crown's long axis and occlusal plane, on the photographs, were executed by a single researcher.

\section{Statistical analysis}

To determine systematic method error, 30 photographs (15 of maxillary canines and 15 of mandibular canines) were taken and measured again, thirty days after the first measurement by the same researcher. The T-paired test was used to evaluate the measurement accuracy (significance level of $5 \%$ ). Casual error was evaluated by the Dahlberg ${ }^{12}$ (1940) formula.

In order to compare angulation averages of maxillary and mandibular canines in Angle Class II and III malocclusions, the T-test for independent samples was used, with a significance level of $5 \%$.

Statistical tests were performed by Statistica for Windows software (Statistica for Windows 6.0; Statsoft, Tulsa, OK, USA).

\section{Results}

T-paired test results did not show any significant differences between the measurements (significance level of $5 \%$ ). Dahlberg's error ranged between 0.1 and 0.2 , indicating good agreement.

In Table 1, the T-test for independent samples results for canine angulation in Angle Class II and III are shown. There was no significant difference $(\mathrm{p} \leq 0.05)$ between groups, when the maxillary canine angulations were compared (Table 1). The mandibular canine angulations in group 2 were less accentuated (more upright) than in group 1, confirmed by a different statistical behavior.

\section{Discussion}

Maxillary canine angulations, which were likely to be less angulated in Class II than in Class III malocclusions, did not display this positioning pattern. Maxillary canine angulation values, both in the Class II sample $\left(10.14^{\circ}\right)$ and the Class III sample $\left(11.86^{\circ}\right)$, were very close to $11^{\circ}$, as suggested and obtained by Andrews ${ }^{1}$ through 120 plaster model analyses of normal occlusions (Table 2). If MBT brackets for the maxillary canines $\left(8^{\circ}\right)$ had been used for treatment of the evaluated sample, these would have induced a reduction in canine angulation, which 
Figure 2 "Photographic table", lateral view: A: Nikon 995 camera; $\mathbf{B}$ : horizontal stem; $\mathbf{C}$ : plaster models with plastic template (occlusal plane).

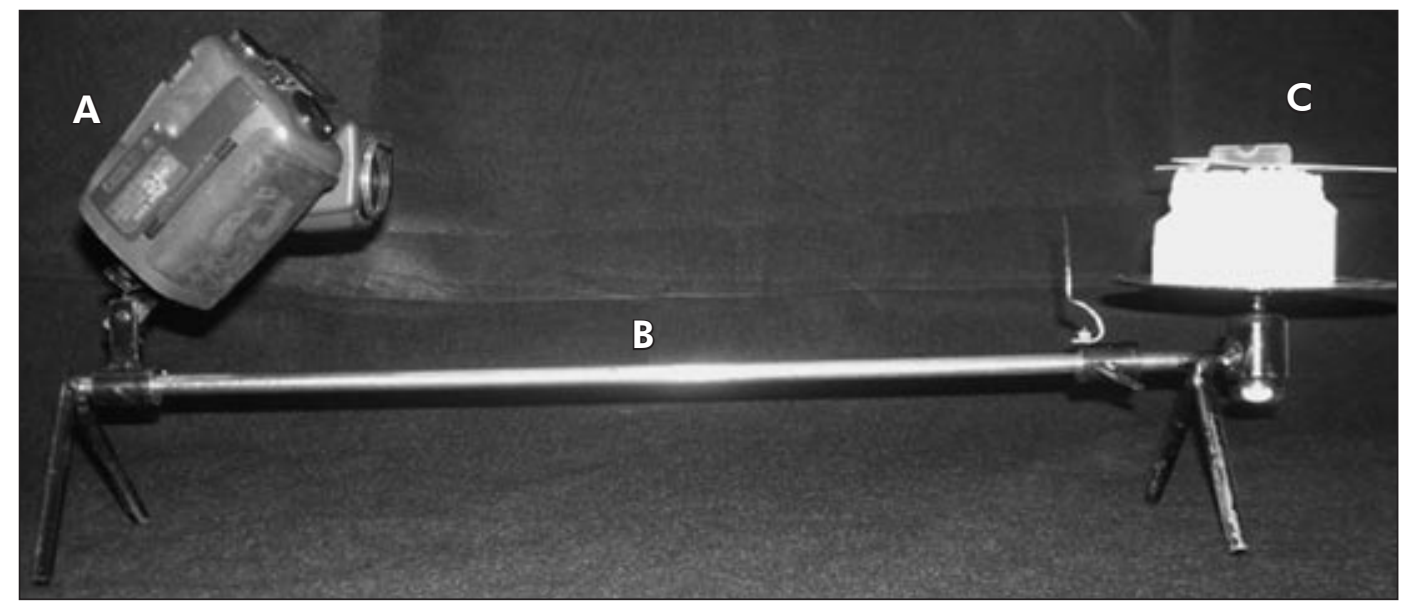

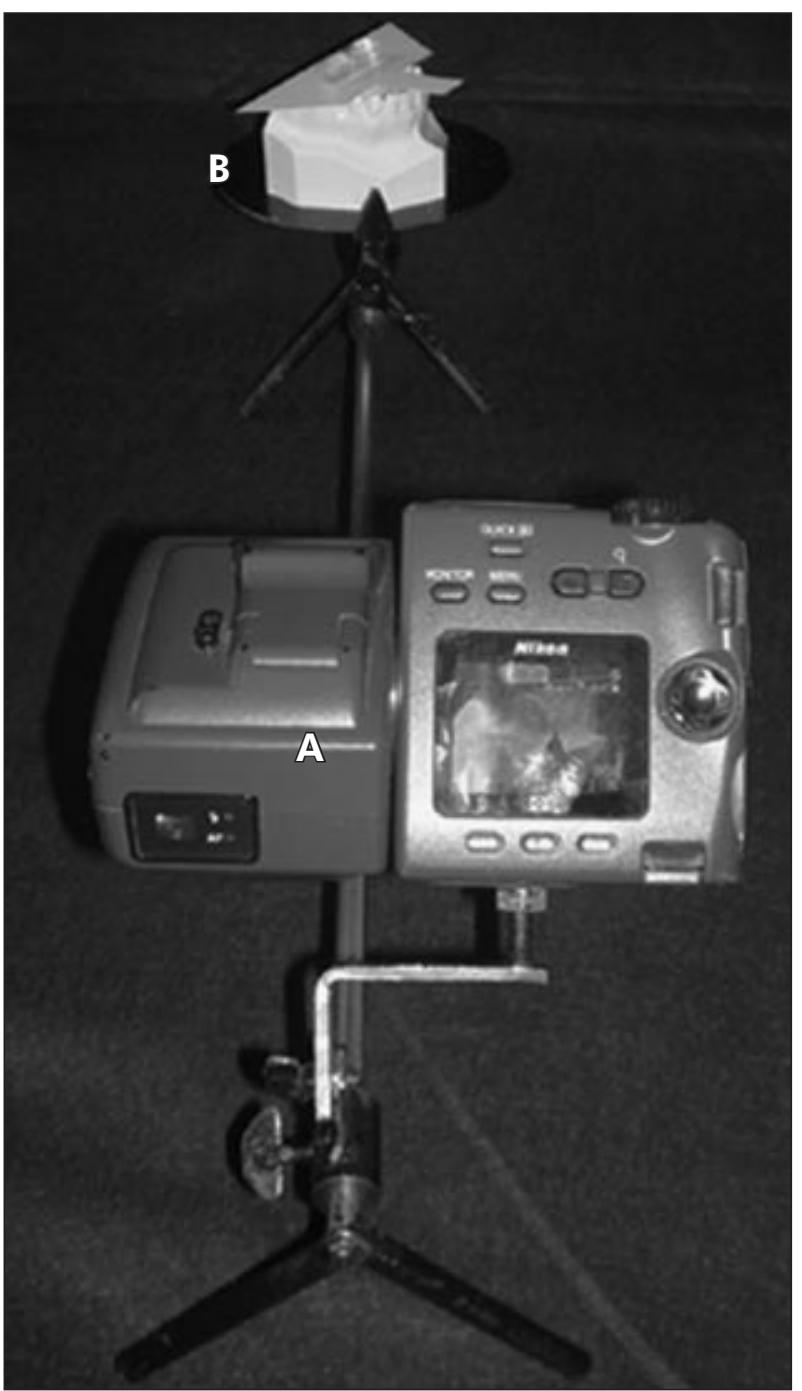

Figure 3 - "Photographic table", superior view (plaster models and camera in position). A: Nikon 995 camera; B: plaster models with plastic template (occlusal plane).

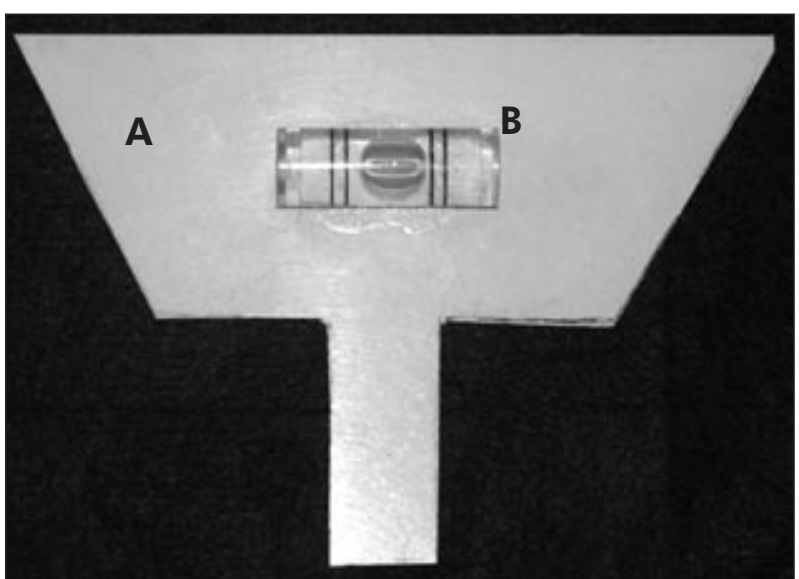

Figure 4 - Plastic template representing occlusal plane and adapted civil construction leveling instrument. A: plastic template; B: leveling instrument.

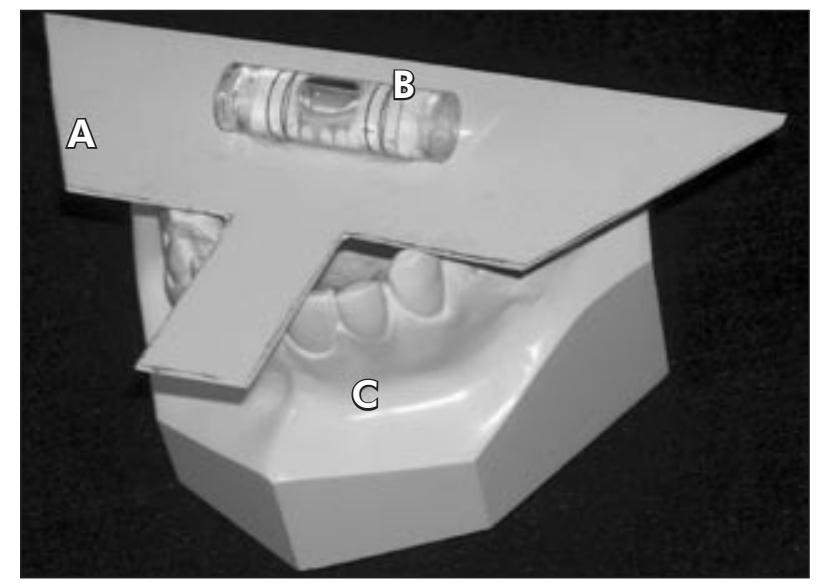

Figure 5 - Plastic template representing occlusal plane and adapted civil construction leveling instrument. A: plastic template; B: leveling instrument; C: plaster model. 


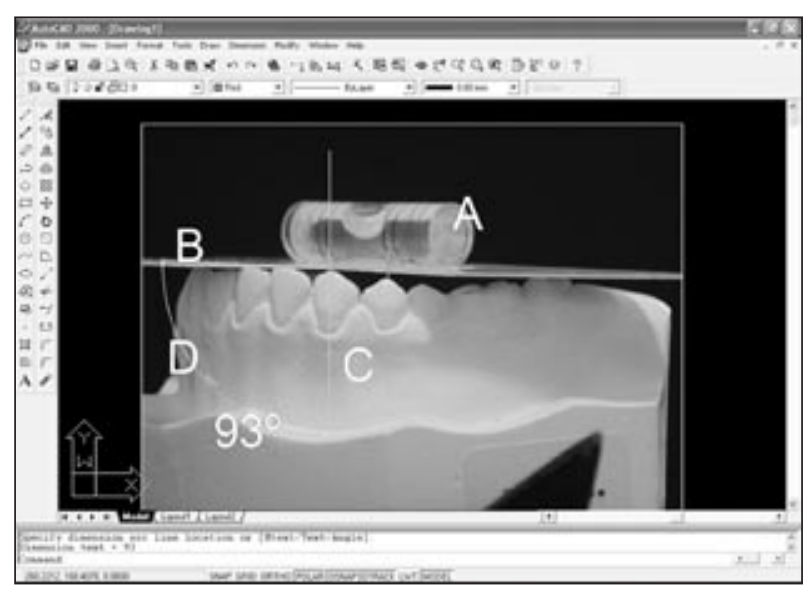

Figure 6 - Occlusal plane and mandibular canine long axis tracings on angulation assessment photograph (A: leveling instrument; B: plastic template (occlusal plane); C: dental crown long axis; $\mathbf{D}$ : angle assessment).

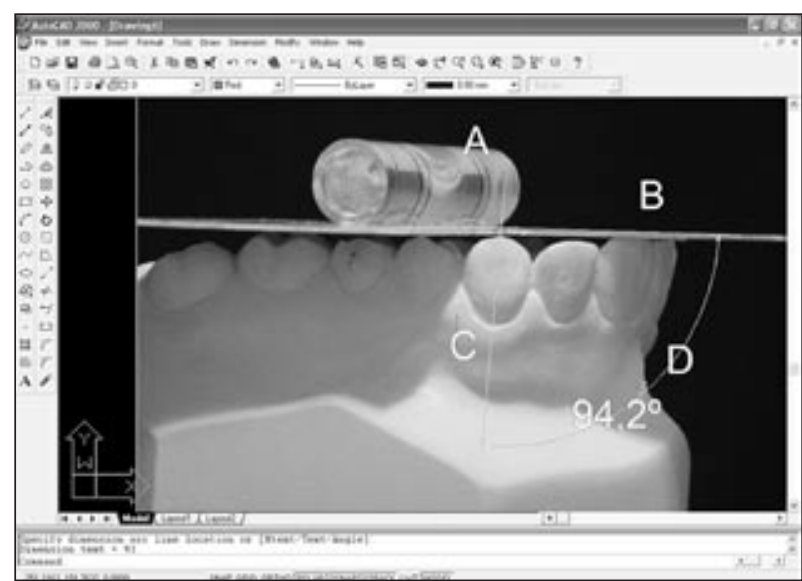

Figure 7 - Occlusal plane and maxillary canine long axis tracings on angulation assessment photograph (A: leveling instrument; B: plastic template (occlusal plane); C: dental crown long axis; D: angle assessment).

Table 1 - T-test results for independent samples. Maxillary $(\mathrm{MxC})$ and mandibular $(\mathrm{MdC})$ canine angulations, in degrees $\left({ }^{\circ}\right)$.

\begin{tabular}{|c|c|c|c|c|c|c|}
\hline & Group 1 - Class II $(n=50)$ & SD & Group 2 - Class III $(n=36)$ & SD & $p$ & \\
\hline \multirow[t]{2}{*}{$\mathrm{M} \times \mathrm{C}$} & $10.14^{\circ}$ & 4.71 & $11.86^{\circ}$ & 4.24 & 0.085 & NS \\
\hline & Group 1 - Class II $(n=42)$ & SD & Group 2 - Class III (n = 38) & SD & $p$ & \\
\hline $\mathrm{MdC}$ & $3.26^{\circ}$ & 5.13 & $0.15^{\circ}$ & 4.55 & 0.005 & * \\
\hline
\end{tabular}

NS: non significant at the $5 \%$ level; *: significant at the $5 \%$ level ( $p \leq 0.05)$; SD: standard deviation.

Table 2 - Bracket angulation prescriptions for mandibular ( $\mathrm{MdC}$ ) and maxillary $(\mathrm{MdC})$ canines recommended by the related literature and results for the samples evaluated.

\begin{tabular}{c|c|c|c|c|c}
\hline & Andrews $^{1}(1972)$ & Roth $^{15}(1976)$ & MBT $^{14}$ & Group 1 - Class II & Group 2-Class III \\
\hline$M \times C$ & $11^{\circ}$ & $13^{\circ}$ & $8^{\circ}$ & $10.14^{\circ}$ & $11.86^{\circ}$ \\
\hline$M d C$ & $5^{\circ}$ & $7^{\circ}$ & $3^{\circ}$ & $3.26^{\circ}$ & $0.15^{\circ}$ \\
\hline
\end{tabular}

would have been interesting for Class II camouflage. With reduced angulation, these teeth would occupy a smaller space in the dental arch, allowing extra space reduction (diastemata) by incisor retraction and a consequently decreased overjet. However, if the same bracket was used for Class III camouflage treatment, it would have induced an average $3.86^{\circ}$ of maxillary canine uprightness, which would not be favorable to orthodontic compensation, because it would result in diastemata that should be closed through aesthetic restoration treatment or anterior teeth retraction. Both procedures can be avoided with an individualized bonding of these teeth. ${ }^{4}$
The mandibular canine angulation in the Class II sample $\left(3.26^{\circ}\right)$ was close to values that have been found by Andrews ${ }^{1}$ (1972) and have been recommended by most authors for mandibular canines ${ }^{13,14}$ (Table 2). Nevertheless, mandibular canine angulation in the Angle Class III sample $\left(0.15^{\circ}\right)$ substantially differed from the values that have been found for the normal occlusion sample ${ }^{1}$ and from bracket prescriptions that have been suggested by different techniques and authors. ${ }^{6,715}$ Therefore, a tendency was observed towards mandibular canine uprightness in the Angle Class III sample, which configures a compensatory coronary positioning pattern for a 
skeletal bases relationship.

If the Roth technique bracket $\left(7^{\circ}\right)$ had been used, for Angle Class III camouflage treatment, this would have induced an increase in mandibular canine angulation, which would have not been interesting for Class III patients because it would have led to the loss of "natural compensation" in coronary angulation, and then to a larger canine space occupation in the dental arch. This would have led to a more protruded position of the mandibular incisors and decreased overjet. Consequently, the selected bracket for group 2 treatment should have an angulation close to zero, resulting in the maintenance of mandibular canine angulation. ${ }^{3}$

The measurement method of the dental crown's long axis angulation, used in this study, proved highly reproducible, because of the few systematic and casual errors found. This method using the "photographic table" and AutoCAD 2000 software showed precision, since this software allowed the use of one or more decimals, thus increasing measurement accuracy.

\section{Clinical implications}

Although an accentuated variability in the long axis angulations of the dental crowns measured in plaster models occurred in this study, a specific coronary positioning pattern can be observed for mandibular canines, mainly in Angle Class III mal-

\section{References}

1. Andrews LF. The six keys to normal occlusion. Am J Orthod. 1972;62(3):296-309.

2. Andrews LF. Straight-Wire: the concept and appliance. San Diego: L. A. Wells; 1989. 159 p.

3. Capelozza Filho L, Silva Filho OG, Ozawa TO, Cavassan AO. Individualização de braquetes na técnica Straight wire: revisão de conceitos e sugestão de indicações para uso. R Dental Press Ortodon Ortop Facial. 1999;4(4):87-106.

4. Holdaway RA. Bracket angulation as applied to the edgewise appliance. Angle Orthod. 1952;22(4):227-36.

5. Proffit WR. Ortodontia Contemporânea. Rio de Janeiro: Guanabara Koogan; 1995. 325 p.

6. Graber TM, Vanarsdall Jr RL. Ortodontia: princípios e técnicas atuais. Rio de Janeiro: Guanabara Koogan; 1996.

7. Strang RHW. Factors associated with successful orthodontic treatment. Am J Orthod. 1952;38(10):790-800. occlusions. This considered, clinicians should pay attention to this angular detail when executing orthodontic camouflage case planning, in order to allow fixed appliance bonding to meet or create the conditions needed for a successful compensation outcome. With a careful bonding procedure and skilled wire bending, clinicians can improve the orthodontic finishing quality of camouflage cases, without using extra stocks of preadjusted brackets for Angle Class II and III treatment. We suggest individualized clinical and plaster model evaluations of the dental crown's long axis with the intention of guiding camouflage treatment conduct, for maintaining the existing angulations or obtaining them. A clinician's diagnosis should be predominant, whereas brackets should be instruments for malocclusion correction. Brackets, as it happens in some cases, should not be considered as miraculous solutions to all problems, predestining the orthodontist to the sad act of "not thinking."

\section{Conclusions}

1. There was no difference in angulations of maxillary canines between Angle Class II and III malocclusions.

2. There was a difference in the angulation of mandibular canines between Angle Class II and III malocclusions.

8. Sangcharearn Y, Ho C. Upper incisor angulation and its effect on molar relationships. Angle Orthod. 2007;77(2):221-5.

9. O’Higgins EA, Kirschen RH, Lee RT. The influence of maxillary incisor inclination on arch length. Br J Orthod. 1999;26(2):97-102.

10. Almeida-Pedrin RR, Pinzan A, Almeida RR, Ursi W, Almeida MR. Panoramic evaluation of mesiodistal axial inclinations of maxillary anterior teeth in orthodontically treated subjects. Am J Orthod Dentofacial Orthop. 2006;130(1):56-60.

11. Little R. The irregularity index: a quantitative score of mandibular anterior alignment. Am J Orthod. 1975;68(5):55463.

12. Dahlberg G. Statistical methods for medical and biological students. New York: Interscience; 1940. 184 p.

13. Zanelato ACT, Maltagliati LA, Scanavini MA, Savério M. Método para mensuração das angulações e inclinações das 
coroas dentárias utilizando modelos de gesso. R Dental Press Ortodon Ortop Facial. 2006;1(2):63-73.

14. Bennett J, McLaughlin R. Orthodontic Treatment Mechanics and the Preadjusted Appliance. London: Mosby-Wolfe; 1993.
15. Roth RH. Five year clinical evaluation of the Andrews straightwire appliance. J Clin Orthod. 1976;10(11):836-50. 